of a fluid, easily digested diet and, above all, by the free administration of alcohol in large doses which are well borne in this disease. Tepid sponging with vinegar and water is comforting to the patient and tends to reduce the temperature. Immersing the patient in a cold bath for ten minutes, which is cooled gradually three degrees lower, followed by the employment of a cold douche, may be tried in desperate cases. Poultices applied to the hypogastrium are beneficial in peritonitic cases and for the same purpose ice-bags may be used. The subcutaneous injection of normal saline solution is a valuable remedy, assisting in the elimination of toxic material.

Drugs.-Quinine is still a drug upon which reliance may be placed in the treatment of puerperal infection but $I$ do not recommend you to give it in very large doses, for I have found that smaller doses are quite as efficacious. Sulphate of quinine given in doses of from three to six grains every three or four hours, combined with carbonate of ammonia in an effervescent mixture, is a good prescription. To this may be added tincture of digitalis, tincture of nux vomica, or liquor strychninæ hydrochloratis, according to the condition of the pulse. This effervescent mixture can be taken even in the presence of the nausea and loathing of food which are so common in this disease. Another drug which is very valuable in puerperal infection is calomel which should be given in frequently repeated small doses in order to maintain a slight amount of diarrhœea.

In two severe cases which $I$ recently saw in consultation the administration of calomel had more effect in reducing temperature than large doses of quinine. When quinine and calomel were given together the temperature fell and the patient appeared to be better, but when quinine was given alone no lowering effect on the temperature was noted; indeed, it became slightly elevated. Calomel was given alone and a marked improvement resulted. In one of these cases the temperature rose to $107^{\circ} \mathrm{F}$., but under this treatment both patients completely recovered. During the administration of calomel you should watch for signs of mercurialism. This does not happen so frequently if diarrhoea is produced by the medicine. In one patient who exhibited marked tenderness of the gums the calomel did not produce diarrhœa. When signs of mercurialism exist the drug should be discontinued and sulphate of magnesia should be given. As the condition of the patient improves on the quinine and calomel treatment a change may be made and large doses of perchloride of iron may be substituted, together with sulphate of magnesia to keep the bowels acting regularly. If you give the perchloride of iron when there are nausea and slight vomiting it is not well borne by the stomach, whereas the effervescent quinine mixture rarely disagrees. I advise you, then, to begin with quinine and calomel and in the later stages to administer perchloride of iron and sulphate of magnesia. For the relief of pain, if severe, some preparation of opium may be required. You may inject morphine subcutaneously or give it in a suppository; but $I$ believe it is better to be avoided. It is not wise to attempt to control the diarrhoea unless it is excessive and then the administration of Dover's powder will be found useful, given in doses of from ten to 30 grains.

Surgical treatment.-The presence of a purulent collection in the pelvis calls for prompt surgical treatment. Parametric abscesses must be opened and drained. Where the pus is situated in the lumen of the Fallopian tubes (pyosalpinx) or in the substance of the ovary (ovarian abscess) immediate operation is required. If the swellings are adherent and accessible from below the pus should be evacuated by vaginal section; in other cases the abdominal route is indicated. Hysterectomy has been advocated and adopted in the treatment of puerperal infection but it has only a limited application. Where a general infection is present the removal of the uterus is not only attended by very grave risk but could not be expected to benefit the patient. If, however, there is localised infection confined to the uterine walls hysterectomy is indicated and the results obtained are good. Abscess formation in the uterine walls and infected myomata are the conditions which usually call for this operation. In those distressing cases of criminal abortion where the uterine wall has been perforated hysterectomy might be tried if the general condition of the patient were favourable. As an adjunct to other methods of intrauterine treatment, especially where peritonitis exists, an opening may be made into Douglas's pouch by incising the posterior vaginal wall. This method was strongly antrocated by the late Dr. Pryor of New York, who also recommended packing the pelvis with gauze. It is better, however, to drain the pelvis with one strip of gauze which should be removed in 48 hours. A gauze drain acts well if the peritoneal effusion is serous. If it is purulent a tube is to be preferred.

\section{A REPORT ON 100 CONSECUTIVE ABDO- MINAL HYSTERECTOMIES (ATTENDED WITH RECOVERY), PERFORMED AT THE MIDDLESEX HOSPITAL AND THE CHELSEA HOS- PITAL FOR WOMEN.}

\section{BY J. BLAND-SUTTON, F.R.C.S. ENG.,}

SURGEON TO THE CHELSEA HOSPITAL FOR WOMEN; AND SURGEON TO OUT-PATIENTS, MIDDLESEX HOSPITAL.

Some cynics among surgeons regard statistics as "lies in figures" calculated to impose upon the credulous. It is somewhat interesting in this connexion to mention that a statistician of some note who flourished in 1660, Herman Conring, was a professor of medicine and politics. It is quite certain that in medicine, using the term in its broadest sense, statistics or the "employment of figures" is an important means of investigation. Indeed, whatever view cynical writers take in regard to the use of statistics "it is impossible to get over the fact that in meteorology, medicine, and other physical sciences statistical inquiries are plainly and obviously examples of the employment of a method, like microscopy, spectrum analysis, or the use of the telescope" (Hooper). It is worth recalling that one of the earliest examples of statistical writing, from the medical point of view, in this country dealt with Bills of Mortality relating to London, 1666. In considering a statistical statement of any kind the first thing is to understand the point or points requiring elucidation and the source of the facts. The object of the present communication is to demonstrate that with the strict application of Listerian principles in the form known as aseptic surgery it is possible for a surgeon to perform abdominal hysterectomy successfully in a well-found hospital 100 times consecutively for a variety of uterine diseases. The abstracts of cases supporting this statement have been compared with the hospital books by the officials in charge of them at the time the operations were performed. $\mathrm{Mr}$. F. Lionel Provis and Mr. J. Howell Evans allow me to state that they verified the references for the Chelsea Hospital for Women; whilst Dr. W. F. Victor Bonney and Mr. Aslett Baldwin sanction the statement that they have verified the references to the patients treated at the Middlesex Hospital. An account of the first 58 cases in the list appeared in the Clinieal Journal of April 20th, 1904, p. 1, but in the present communication an additional (or supplemental) account is given of the patients' condition. For these subsequent notes I alone am responsible and the source of the information is given in all cases where the request met with success. Great care and pains have been taken to secure these reports in order to show that in the majority of instances the patients derived benefit from the operation, for it is necessary to remember that recovery from an operation is not always equivalent to success from an operation. A careful study of these supplemental reports is very instructive and shows that in the majority of cases the patients require six months or even a year to obtain the full benefit. of the operation, especially those who were profoundly. anæmic from profuse menorrhagia.

It is important to point out that these operations were not only performed in a public institution but were carried out in the hospital theatre accessible to qualified medical men and women; every operation in the list was witnessed by members of the profession other than those of the official staff of the hospital. In no case was an exploratory operation performed or any case abandoned as too difficult. Operative treatment was not refused to any patient save those with very extensive cancer and, except in this drfadful disease, there was no picking and choosing. Throughout this communication the term "sub-total hysterectomy" will replace the cumbersome expression "supravaginal hysterectomy" as signifying the removal of the body of the uterus with a. 
variable portion of its neck. This change of terms is desirable, for the operation which has given me the best results is not quite what would be called a "panhysterectomy" yet it is something much more than is usually covered by the phrase "supravaginal" hysterectomy. The careful study of the subsequent course of patients after supraraginal hysterectomy led observant operators to notice that those cases did best in whom the supravaginal cervix had been most freely removed; as a matter of fact, in the majority of my operations classed as supravaginal hysterectomy the only part of the uterus left is the vaginal portion of the cervix and after the operation is completed the united surfaces of the peritoneum merely appear as a slightly raised ridge across the pelvic floor, so that a surgeon inspecting the operation area from above would imagine that a total hysterectomy had been performed. On the other hand, if the cervix be examined from the vagina six months after the operation it will appear natural to the eye and touch. This is a matter of importance, as the operation in no way impairs the pelvic floor or hinders the function of the vagina. For this method the term in familar use among Parisian surgeons, "sub-total hysterectomy," is peculiarly suitable. The morbid conditions of the uterus which rendered radical operation necessary in these patients fall into five groups : fibroids and adenomyoma, 81; cancer, four; sarcoma, one chronic inflammatory disease of the uterus, four; and fibrosis, ten cases ; these causes indicate the widening scope of hysterectomy.

Fibroids.-In 81 patients hysterectomy was performed for these tumours, including two cases of the remarkable disease known as diffuse adenomyoma of the uterus. The commonest condition which induced these patients to submit to operation was profuse and long-continued bleeding from the uterus. The ages of the patients varied from 27 to 69 years. It is necessary to draw attention to the fact that out of a total of 81 pysterectomies for fibroids 13 of the patients had reached the age of 50 years and upwards and in each of them it was necessary to perform a serious operation for a disease which is generally believed to become harmless about the forty-eighth year of a woman's life. Two of these are worth some special remarks. Case 72 had been known to have a uterine fibroid many years and she ceased to menstruate in her fiftieth year. In consequence the tumour diminished very materially. When she attained her sixtieth year the fibroid began to cause so much trouble with the bowel and bladder that she had to seek relief. A large tumour blocked up the inlet of the pelvis and pushed the cervix low into the vagina. At the operation I found a large conical fibroid firmly fixed in the pelvis like a cork; it required a fair effort to extract it and, as in all those exceptional cases which require surgical interference after the menopause, the operation was singularly easy and almost bloodless. The tumour had a transverse diameter of $4 \frac{1}{2}$ inches, a vertical diameter of $5 \frac{1}{2}$ inches, and in horizontal circumference measured $13 \frac{1}{2}$ inches. The patient was a spinster of average proportions, so that these measurements will afford some indication of the tightness with which this fibroid blocked the pelvis.

The oldest case in this series is in some respects the most interesting. The patient (No. 91 in the list) had attained her sixty-ninth year and she knew for a quarter of a century that her abdomen contained a tumour which by its size and weight had been a source of great inconvenience and often actual distress. This woman when placed under my care had been suffering from profuse uterine hæmorrhage and it was on this account that she deliberately sought the aid of surgery. The tumour equalled in size and hardness the head of a man. She was very fat, had an umbilical hernia, and unfortunately her urine contained sugar to the extent of 12 grains to the ounce. By rest and diet the amount of sugar diminished and I performed hysterectomy. The uterus contained a fibroid with an average diameter of 12 inches (30 centimetres) which yielded the odour of stale fish and the uterine cavity contained a degenerating tumour with the microscopic characters of cancer. On account of the glycosuria the operation was quickly completed, occupying from the time the anæsthesia was begun to the application of the dressing 22 minutes. The patient recovered easily and quickly. She left the hospital on the eighteenth day for her home. In a letter reporting her subsequent condition Mr. J. C. R. Braine-Hartnell, in expressing his satisfaction that the operation had been undertaken, states that the previous 20 years of her life had been " 20 years of misery." Such a case tells its own tale.
If I had been bent on selecting cases for the purpose of making good statistics it would have been easy in regard to this old lady to urge the presence of sugar in the urine as a bar to operation, and doubtless some practitioners would have deemed it a manifestation of surgical prudence. It is, however, useful to remember that operating on bad cases is very apt to ruin statistics but it frequently saves lives, and this is the main consideration.

Diffuse adenomyoma.-Among the fibroids there were two examples of this condition; they are included with them, because, in these two cases, the uterus also contained typical fibroids, and the clinical signs of the disease are indistinguishable from those which indicate the existence of submucous fibroids and the treatment eventually required is the same-namely, hysterectomy-on account of the longcontinuing exhausting menorrhagia, which rest, drugs, and repeated curetting fail to cure.

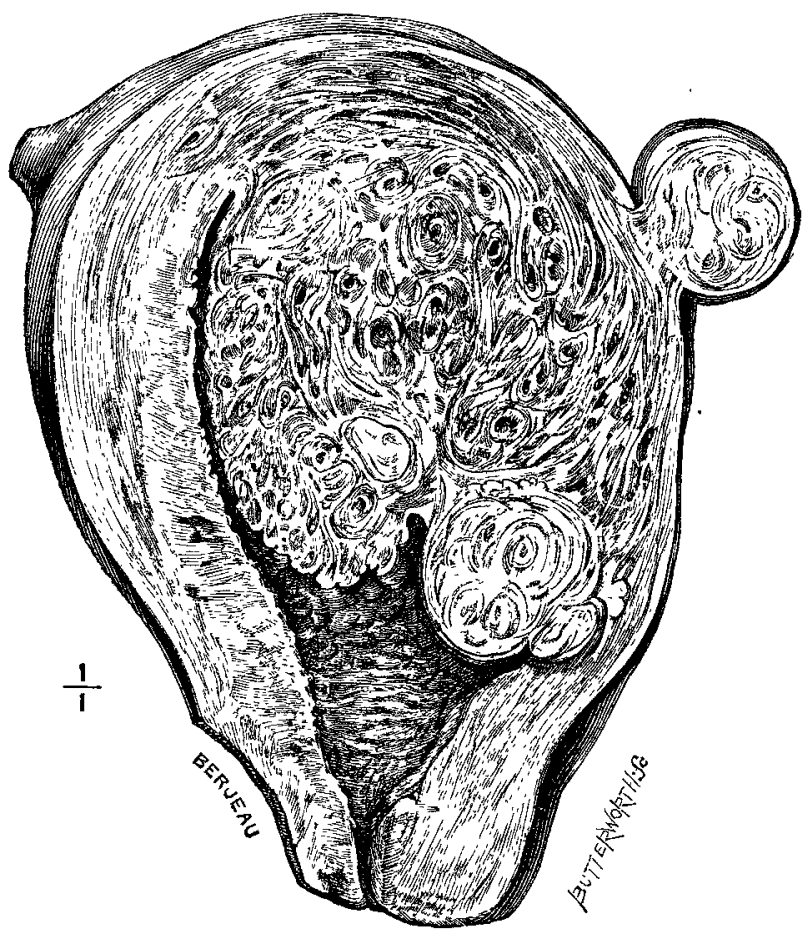

A uterus in sagittal section showing diffuse adenomyoma, from a spinster 32 years of age. The gland spaces were cystic and filled with gelatinous material.

Fibrosis of the uterus.-The prominent symptom which renders hysterectomy necessary in this disease may be described as rebellious menorrhagia, for it defies rest, drugs, and repeated curettings. Dr. A. H. Freeland Barbour recently brought a case of this disease before the Obstetrical Society of Edinburgh ${ }^{1}$ and the communication clearly shows that he appreciates the leading features of the morbid anatomy of this affection, which, as be states, is essentially one affecting the arteries of the endometrium before the menopause. Dr. Barbour also recognises the most important clinical aspect of the condition-namely, the manner in which the bleeding and the enlargement of the uterus simulate cancer of the corporeal endometrium and that in the way of treatment hysterectomy alone gives good results.

In the cases in the following list the operation performed was sub-total hysterectomy unless otherwise specified.

CASE 1.-A sir gle woman, aged 49 years ; fibroid; profound anæmia : Jan. 19th, 1903. This patient had been an invalid for several years. She writes, Jan. 10th, 1905: "I have been earning my living as month after the operation." " Oth after the operation."

CASE 2.- A married woman, aged 33 years; fibroid; hæmorrhage and pain; Jan. 19th, 1903. Bilateral oophorectomy had been performed five years previously for menornagia but withont goon consequences. Reported in good health from $A$ medical attendant.

CASE 3. - A single woman, aged 44 years; fibroid; hæmorrhage; Jan. 19th, 1903. "I am better now than I have been for the last ten years and people cannot understand how it is that I look so "well after all the misery that I have been through before the operation." Patient's letter, Jan. 7th, 1905.

CASE 4.-A married woman, aged 49 years; adenomyoma; Jan. 26th, 1903. "I saw the patient to-day; she expressed herself as feeling perfectly well; in fact, better than she had felt for years." Letter from medical attendant, Jan. 5th, 1905.

CASE 5.-A married woman, aged 45 years; fibroid; hæmorrhage Feb. 2nd, 1903. "I consider that I am very fortunate to be so well as I am as $I$ have had no pain in my stomach since the operation, the only 
thing I perspire very much and flushing, but that is nothing to the pain 1 was in before the operation." Patient's letter, Jan. 11th, 1905. CASE 6.-A married woman, ager 35 years. A very large fibroid ;
March 2nd, 1903. Reported herself on her birthday, Jan. 9th, 1905. In excellent health.

CASE 7.-A married woman, aged 35 years. Fibrosis ; menorrhagia ; March 2nd, 1903. In excellent health September, 1904, and placed her sister under my care for hysterectomy (see Case 82 ).

CASE 8.-An unmarried woman, aged 48 years. Fibroids; hæmorrhage; March 9th; 1903 . Re-entered the hospital for vesical calculus, July, 1904. Uterine stump quite free from the bladder.

CASE 9.-An unmarried woman, aged 48 years. Fibroids ; hæmorhage; March 16th, 1903 . Reported herself one month after operation with cedema of one leg.

CASE 10.-A married woman, aged 52 years. Fibrolds ; bæmorrhage : April 6th, 1903. “ 'I really en

CASE 11. - A married woman, aged 35 years. Fibroids (? sarcoma), April 13th, 1903. In good health Jan. 10th, 1905. Letter from patient. CASE 12.-An unmarried woman, aged 45 years. Large and rapidly growing fibroid; April 13th, 1903. This patient has been under treatment at home for recrudescence of disease in her knee which afficted her when she was a child. Letter from patient, January, 1905.

CASE 13.-An unmarried woman, aged 35 years. Fibroids; hæmorrhage; April 20th, 1903. "My health is really good and strong, I am rhage; April 20th, 1903. "My health is really good and strong, I am Previous to operation my life was unbearable." Patient's letter, Jan. 16th, 1905.

CASE 14-A married woman, aged 38 years. Fibroids; profound anæmia; May 4th, 1903. "My health is very satisfactory." Letter from patient, Jan. 6th, 1905

CASE 15.-A married woman, aged 53 years. Fibroids; bilateral ovarian cysts; May 11th, 1903. "I have greatly improved." Patient's letter, Jan. 7th, 1905.

CAsE 16.-A married woman, aged 37 years. Fibroids; bilateral pyosalpinx ; May 11th, 1903. "I am in good health except that I have patient, Jan. 6th, 1905

CASE 17. - A married woman, aged 43 years. Fibrosis: profuse menorrhagia ; May 25th, 1903 . "I am fairly well with the exception of frequent headaches and nerve troubles." Letter from patient, Jan. 15th. 1905.

CASE 18. - An unmarried woman, aged 49 years. Fibroids ; profuse menorrhagia; June 1st, 1903.

CASE 19.-A married woman, aged 54 years. Fibrosis; menorrhagia; June 15th, 1903. Left for Ceylon some weeks later.

CASE 20. - An unmarried woman, aged 45 years. Fibroids, very large; July 6th, 1903. "Feeling better than I have for years." Jan. 8th. 1905 . CASE 21. - An unmarried woman, aged 47 years. Fibroids, very large, July 7th, 1903. In the October following (the operation) was able to commence work again. Patient's letter, Jan. 7th, 1905.

CASE 22. - An unmarried woman, aged 52 vears. Fibroids, very large July 11th, 1903. " I am very well." Jan. 7th, 1905.

CASE 23.-A married woman, aged 37 years. Fibroids ; hæmorrhage cyst of the right ovary; July 27th, 1903. (Middlesex Hospital.) Enjoying the best of heaith." Patient's letter, Jan. 10th, 1905.

CASE 24.-An unmarried woman, aged 46 vears. Cancer of the body returned, "Gone away," Jan. 10th, 1905.

CASE 25. - An unmarried woman, aged 53 vears. Fibroids and cancer of the body of the uterus; August 13th, 1903. (Middlesex Hospital.)
This case was drained and she left hospital with a sinus. This closed some months later. She now complains of pain in the left side. Jan. 9 th, 1905

CASE 26.-A married woman, aged 46 years. Fibroid and ovarian dermoid; August 17th, 1903. (Middlesex Hospital.) "She enjoys better Jan. 10th, 1905

CASE 27. - A married woman, aged 51 years. Fibroids ; hæmorrbage August 20th, 1903 . (Middlesex Hospital.) "Is perfectly well as Jan. 9th, 1905 .

OASE 28. - An unmarried woman, aged 47 years. Fibroid, degenerating; hæmorrhage ; Sept. 7th, 1903. " I am beginning to feel much stronger." Letter, Jan. 16th, 1905. As a matter of fact, I can state that this patient is very well.

CASE 29.-A married woman, aged 45 years. Fibroid, degenerating; hæmorrhage; Sept. 7th, 1903 . "Her condition is much better than it has been for years." Letter from medical attendant, Jan. 6th, 1905. CASE 30.-An unmarried woman, aged 42 years. Fibroid; profound anæmia; Sept. 7th, 1903. In good health, September, 1904. Personal

CASE 31.-A married woman, aged 24 years. Septic endometritis Sept. 7th, 1903. In good health when she left for Africa. Autumn CASE 32.-A widow, aged 49 years. Fibroid; cancer of tube Sept. 14th, 1903 . Known to

contemplating re-marriage. CASE 33. - A married woman, aged 32 years. Fibroid; hæmorrhage
Sept. 14th, 1903. "You will be pleased to hear that I was able to conduct and manage more business last summer than in any previous year." Jan. 7th, 1905

CASE 34.-A married woman, aged 31 years. Fibroid; hæmorrhage and degeneration; Sept. 21st, 1903. "For the relief of the operation am most thankful. I hardly know myself, I feel so well." Patient's letter, Jan. 26th, 1905.

CASF 35.-A married woman, aged 44 years. Fibrosis; hamorrhage
Sept. 28th, 1903. Good report from medical attendant, Jan. 6th, 1905 . Sept. 28th, 1903 . Good report from medical attendant, Jan. 6th, 1905 .
CASE 36.-An unmarried woman, aged 40 rears. Fibroid; profoun anæmia; Oct. 19th, 1903 . Had some trouble from a stitch but is now all right. Jan. 13th, 1905.

CASE 37.-An unmarried woman, ager 23 years. Cancer of the cervix.
Total hysterectomy, Nov. 2nd, 1903 . Seen at frequent intervals since operation ; in good healtb, October, 1904.

CASE 38. - A married woman, aged 33 years. Fibrosis. Suspected to
be cancer of the cervix; Nov, 9 th, 1903 . She is tirst-rate, is fat, and looks well. Let ter from medical attendant, Jan. $10 \mathrm{th}, 1905$.

CASE 39.-A married woman, aged 38 years. Fibroid, very large.
Dermoid; Nov. 16th. 1903. " I have now better health than I have ever had." Jan. 7th, 1905.

CASE 40.-An unmarried woman, aged 44 years. Fibroid. large and growing; Nov. 23rd, 1903. "Fräulein —— is so well since her opera tion." Letter from her friend (Case 1), Jan. 10th, 1905.

CASE 41.-An nnmarried woman, aged 38 years. Fibroid: profound anæmia, Nov. 30th, 1903. "My condition is, on the whole, very satisfactory." Patient's letter, Jan. 11th, 1905

CASE 42.- An unmarried woman, aged 55 years. Fibroids; pain an. 11th, 1904. Convalescence slow, and Jan. 5th, 1905, her medica attendant writes: "Is now able to take up her school duties so that I think it is remarkable."

CASE 43.- An unmarried woman, aged 50 years. Cervix fibroid; retention of urine; Jan. 11th, 1904. "I still feel a weakness in the left side but beyond that I feel better and can walk better than I have done for some years." Letter from patient, Jan. 7th. 1905.

CaSE 44.-An unmarried woman, aged 59 years. Cancer of the body of the uterus; total hysterectomy; Jan. 18th, 1904. Suspicion
recurrence, March 18th, 1905. Letter from medical attendant.

CASE 45.-A married woman, aged 37 years. Fibroids, septic; Jan. 18th, 1904. In excellent health. Seen personally on Jan. 23rd,

CASE 46.-An unmarried woman, aged 42 years. Cervix fibroid CASE 46.-An unmarried woman, aged 42 years. Cervix fibroid ;
Jan. 25th, 1904. "My health is now excellent." Letter, Jan. 7th, 1905.

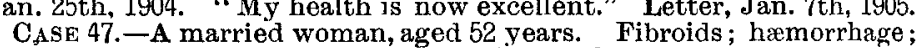
CASE 47. A married woman, aged 52 years. Fibroids; hæmorrhage;
Feb. 8th, 1904. Recovered slowly. "She looks the picture of health and feels quite well." Letter from medical attendant, April 2nd, 1905. nd feels quite well." Letter from medical attendant, April 2nd, 1905.
CASE 48-A married woman, aged 42 vears. Fibrosis ; profuse menorrhagia; Feb. 15th, 1904 . Sent a post-card from the Matterhorn show that she could climb a mountain in the summer, 1904

CASE 49.-An unmarried woman, aged 37 years. Subserous fibroid and diffuse adenomyoma; very profuse menorrhagia; March 7th, 1904. This patient, a surgical nurse, suffered from asthma and it was thought that if the metrorrhagia was stopped the severity of the asthmatic
attacks might be lessened. This hope has not been realised, though the patient's general condition is greatly improved.

CASE 50.-A married woman, aged 44 years. Fibroid; very large and painful; March 7th, 1904. This patient (a monthly nurse) writes, I have to complain of, I have to bold my abdomen just by the navel when I cough or sneeze.

CASE 51.-An unmarried woman, aged 43 years. Fibroid; profuse metrorrhagia ; March 14th, 1904 . This patient, a surgical nurse, writes kind."

CASE 52.-An unmarried woman, aged 42 years. Fibroid; excessive menstruation; anæmia; March 21st, 1904. "Patient never remembers feeling better." Letter from medical attendant Feb. 27th, 1905.

CASE 53.-A married woman, aged 33 years. Fibroid; menorrhagia; March 21st, 1904. Total hysterectomy. Good report from the patient March 1st, 1905.

CASE 54.-A married woman, aged 48 years. Fibroid ; metrorrhagia; bilateral hydrosalpinx; March 21st, 1904. Patient is very well. Letter from medical attendant, Feb. 27th, 1905

CASE 55.-A married woman, aged 45 years. Cervix fibroid; menorrhagia; March 28th, 1904. Patient reports herself in good health. Let,ter, Feb. 28th. 1905

CASE 56.-A married woman, aged 43 years. Sarcomatous fibroid; ntense pain; March 28th. 1904. Patient died in June, 1904. Dr. writes that she had much less pain after the operation.

CASE 57.-An unmarried woman, aged 29 years. Fibroid; soft myxomatous ; menorrhagia; profound (toxic) anæmia; March 29th, 1904. Patient keeping in good health. Letter, Feb. 28th, 1905.

CASE 58.-An unmarried woman, aged 56 years. Fibroids; pain and drsuria; April 12th, 1904. Convalescence slow but satisfactory. Letter from patient, Feb. $27 \mathrm{th}, 1905$.

CASE 59.-An unmarried woman, aged 32 years. Fibroids; menorrhagia and pain; April 12th, 1904. In good health December, 1904. CASE 60.-A married woman, aged 52 years. Fibroids; excessive metrorrhagia; April 15th, 1904. Good report from the patient, Feb. 23rd, 1905

CASE 61.-An unmarried woman, aged 39 years. Fibroids; pain; on March 16th, 1903; the left ovary was not removed, nor were there any evidences of tibroids. Soon after this operation she began to suffer from profuse menstruation and pain and the former becamenso profuse as to interfere with active life. She writes, Feb. 28th, 1905: "I am much better since my last operation."

CASE 62.-A married woman, aged 42 years. Fibroids; cystic ovaries CASE 62.- A married woman, aged 42 years. Fibroids; cystic ovaries
and distended Fallopian tubes; April 16th, 1904. (Unable to trace this patient; she was in good condition when she left the hospital.)

CASE 63.-An unmarried woman, aged 41 years. Cervix fibroid; menorrhagia; cancer of the colon discovered in the course of the operation, April 18th, 1904 . Resection of the sigmoid flexure for cance in the Middlesex Hospital, September, 1904. The patient subsequently in good health.

CASE 64.-A married woman, aged 33 years. Chronic inflammatory disease of the uterus, tube, and ovaries; total hysterectomy, April 25th, 1904. Good report from the patient, Feb. 28th, 1905.

CAse 65.-A married woman, aged 31 years. Fibroids; red degeneration; pain and menorrhagia; May 2nd, 1904. April 2nd, 1905, the medical attendant writes: "She is now quite well, but a month or so
after her return home she had an attack of hemiplegia which cleared after her return

up completely."

CAsE 66.-A married woman, aged 40 vears. Fibroids ; profuse menor rhagia; May 9th, 1904. "Health much improved since the operation." Letter from patient, March 16th, 1905

CASE 67.-A married woman, aged 33 years. Fibroids obstructing labour. Total hysterect omy during labour. May 9th, 1904. The patient was seen several times subsequently. In good health January. 1905 . tion of 68 .- A married woman, aged 37 years. Cervix-fibroid ; reten1904. The patient made a slow convalescence. April 2nd, 1905 , the merlical attendant writes: "Looks very well; she has flushings and the symptoms of the menopause."

CASE 69.-An unmarried woman, aged 48 years. Fibroids; May 16th, 
1904. In good health March 13th, 1905. Letter from medical attendant

CASE 70.-An unmarried woman, aged 33 years, Fibroids, monorrhagia, pain; May 30th, 1904 . Convalescence slow but satisfactory. Letter from patient, March 29th, 1905.

CASE 71.-An unmarried woman, aged 47 years. Fibroids; painful micturition ; total hysterectomy, May 30th, 1904. " Health greatly improved since the operation." Letter, March 3rd, 1905

CASE 72.-An unmarried woman, aged 60 years. Fibroid impacted in the pelvis; retention of urine; June 27th, 1904 . The patient was much more comfortable since the operation. Her general health is not good. Letter, March, 3rd, 1905.

C $\triangle$ SE 73.-A married woman, aged 48 years. Fibroids; profuse chos 1905 , in good health.

CASE 74.-A married woman, aged 48 years. Fibroids; menorrhagia July 4th, 1904. The patient was reported well, Feb. 28th, 1905, by her medical attendant.

CASE 75. - A married woman, aged 38 years. Fibrosis ; metrorrhagia July 11th 1904. "The patient is much better." Letter March 3rd,

CASE 76.-An unmarried woman, aged 40 years. Fibroids, pain, and frequent micturition": July 11th, 1904 " "General health fairly good." Letter, March, 1905

CASE 77.-An unmarried woman, aged 33 years. Fibroids ; menorrhagia; July 11th, 1904. Convalescence slow. Letter, March 9th, 1905. CASE 78. - An unmarried woman, aged 27 years. Fibroids, tumour thought to be a solid ovarian before operation, July 26th, 1904 (Middlesex Hospital). "I have been very much better in health since my operation." Letter from patient March 13th, 1905.

CASE 79.-An unmarried woman, aged 50 years. Septic uterus and hydrosalpinx; August 17th, 1904 (Middlesex Hospital). Personal visit in February, 1905. In good health.

CASE 80.-An unmarried woman, aged 51 years. Fibroids; profuse menorrhagia; August 24th, 1904 (Middlesex Hospital). The patient was very well March 2 nd, 1905. Letter from medical attendant.

CASE 81.-A married woman, aged 39 years. Fibrosis ; profuse menorrhagia; Sept. 12th, 1904. Reported to be in good health two months after leaving hospital.

CASE 82.-A married woman, aged 39 years. Fibrosis ; menorrhagia; a chronic invalid ; total hysterectomy, Sept. 26th, 1904. Convalescence slow but satisfactorv. Letter March 29th, 1905.

CASE 83.-An unmarried woman, aged 40 years. Fibroids; metrorrhagia ; Sept. 28th, 1904. (Middlesex Hospital.) The patient (a nurse in a county asylum) says she feels better than she has done for years. Letter, March 28th, 1905.

CASE 84.-A married woman, aged 40 years. Fibroids; metrorrhagia total hysterectomy, Oct. 3rd, 1904. No report since leaving the hospital.

CASE 85.-A married woman, aged 48 years. Fibroids; septic ; continuous metrorrhagia; total hysterectomy, Oct. 3rd, 1904. " Her health has improved wonderfully since the operation." The patient left for

CASE 86.-A married woman, aged 34 vears. Fibroids; Oct. 3rd, 1904.

Very good report from the patient. Letter March, 1905 .

CASE 87.-A married wornan, aged 40 years. Cervix fibroid; tightly impacted and degenerated; Oct. 7th, 1904. The patient had done extraordinarily well ; can do a hard day's work. Letter from medical attendant, March 31 st, 1905

CASE 88.-A married woman, aged 46 years. Fibroicts; three of very large size and one impacted in the pelvis; Nov. 14th, 1904. "My
wife is better now than she has been for years." Letter, March 6th, CASE 89. - A married woman, aged 33 years. Fibrosis; persistent bleeding; Nov. 14th, 1904. Good report from the patient; March 31st 1905.

OASE 90.-A married woman, aged 37 years. Fibroids; menorrhagia marked anæmia; Nov. 2lst, 1904. "My health is better than I have ever had it." Letter from patient, March 3rd, 1905.

CASE 91.-A married woman, aged 69 years. Fibroids; dangerous bleeding; diabet es; sugar ten grains to the ounce; cancer of the body of the uterus: Nov 28th 1904 Her medical attendant writes, April 4th, 1905, that the patient " is wonderfully well."

CASE 92 - A married woman aged 30 vears. Fibroids ; profuse (1904. The patient profuse excellent convalescence.

CASE 93 - An unmarried woman, aged 52 years. Fibroids; pain and CASE 93.- An unmarried woman, aged 52 years. Fibroids ; pain and menor

Oa in a county asvlum and is very 37 . Leater, March 28 , 1905.

bilateral salpingitis ; total hysterectomy, Dec. 5th, 1904 . No report ilateral salpingitis ; total

OASE 95.-A married woman, aged 44 years. Fibroids, small but numerous; protuse metrorrhagia; distended Fallopian tubes ; total numerous; profuse metrorrhagia ; distended Fallopian tubes ; total hysterectomy, Dec. 12th, 1904. The patient has done ext

well. Letter from her medical attendant March 31st, 1905 . CASE 96.-An unmarried woman, aged 48 years. Fibroids ; pain and
frequent micturition; Dec. 19th, 1904. Good report from the patient Feb. 15th, 1905

CASE 97.-A married woman, aged 35 vears. Fibroids ; menorrhagia; profound anamia; Dec. 19th, 1904. Good report from the patient, March 10th, 1905

CASE 98.-A married woman, aged 41 years. Fibroids; menorrhagia ; anæmia; Dec. 19th, 1904. Letter from patient, Feb. 3rd, 1905. "Getting quite strong again."

CASE 99. -An unmarried woman, aged 40 years. Fibroids; hæmorrhage and anæmia ; Dec. 20th, 1904. Good report from the patient.

CASE 100.-An unmarried woman, aged 52 years. Fibroids; hæmorrhage ; Dec. 20th, 1904. "Much stronger and doing well." Letter from patient Feb. 3rd, 1905, and March 20th, 1905

In addition to the 81 patients from whom the uterus was removed for fibroids and diffuse adenomyoma there were eight women in whom myomectomy or enucleation was performed, and one woman, aged 28 years, from whom a large soft fibroid weighing 14 pounds was removed from the round ligament of the uterus. 'This tumour grew into the abdomen like a subserous stalked fibroid. Each of these patients made an uninterrupted recovery. Myomectomy and enucleation are justifiable procedures in women contemplating marriage and in married women so anxious for offspring that they are willing to run serious risks on the chance of obtaining living children. Experience, however, teaches this stern lesson: after the enucleation of a fibroid in the procreative period of life a woman is 20 times more likely to grow more fibroids in her womb than to conceive successfully.

Brook-street, W.

\section{ON PNEUMOCOCCAL SORE-THROAT WITH NOTES OF A FATAL CASE.}

BY W. PASTEUR, M.D. LoND., F.R.C.P. LOND.,

PHYSICIAN TO THE MIDDLESEX HOSPITAL; CONSULTING PHYSICIAN TO THE NORTH-EASTERN HOSPITAL FOR CHILDREN.

AMONG the acute inflammations of the faucial region there is one, pneumococcal angina, which has not apparently as yet received in this country the attention it deserves. At a recent public examination not a single candidate even mentioned this condition in discussing the differential diagnosis of diphtheria. Pneumococcal inflammations of the fauces and larynx are, however, well worthy of attention on account of the close clinical resemblance they may present to other acute inflammations of those regions, especially diphtheria.

The occurrence of inflammatory lesions of various mucous membranes, with or without membranous exudation, in association with pneumonia and broncho-pneumonia has been recognised for many years. A very remarkable case of this kind is recorded by Cary and Lyon. ${ }^{1}$ But examples of primary inflammation of the faucial region are much more uncommon. Jaccoud, ${ }^{2}$ T. K. Monro, ${ }^{3}$ and others have placed on record cases of membranous sore-throat of pneumococcal origin which clinically were very like diphtheria. The appearances in the case I am about to relate differ widely from these and afford a good example of another variety of pneumococcal pharyngitis, the "angine érythémateuse pneumococcique" of French authors.

Referring to the probable frequency of acute membranous tonsillitis and pharyngitis of pneumococcal origin, Foulerton ${ }^{4}$ remarks that "the exact bacteriological identification in these cases is rendered difficult by the fact that the organism is a frequent parasite of the healthy mouth. But the number of cases in which there are the formation of a false membrane and destruction of the superficial layer of the epithelial membrane associated with the presence of the coccus in predominant numbers and without any of the other bacteria -B. diphtheriæ, streptococcus pyogenes, and saccharomyces albicans-which are known to cause similar lesions, leaves little doubt as to the fairly frequent occurrence of an acute membranous pharyngitis due to this cause."

A healthy, well-nourished boy, aged three and a half years, was seized with sudden illness on Oct. 24th, 1903. The prominent symptoms were sore-throat with great pain on deglutition and high fever, which had persisted. There was no initial vomiting nor had there been any signs of laryngea implication or of pulmonary trouble. He had only taken small quantities of milk with much difficulty. He was admitted to the Middlesex Hospital on the fourth day of illness in the following condition. The face was pale with a dusky malar flush. The respirations (40 per minute) were not laboured. The pulse (120) was soft, full, and regular. The glands at the angle of the jaw were moderately swollen on both sides and very tender. The skin was dry and hot (temperature, $103^{\circ} \mathrm{F}$.). There were no signs of desquamation and no puffiness. There was no discharge from the nose or ears. A careful examination of the heart and lungs revealed no abnormal signs. A specimen of urine passed soon after admission gave a positive result to Ehrlich's diazo reaction it was free from albumin. The uvula, soft palate, and faucial pillars on both sides were slightly cedematous and intensely red and glazed. Both tonsils were somewhat swollen and intensely injected. There were no exudation of any kind and

1 American Journal of the Merical Sciences, September, 1901 2 Semaine Médicale, July, 1893

3 Glasgow Medical Journal, vol, 1 vi. 274.

4 Transactions of the Pathological Society of London, vol. liii., p. 293. 